\title{
Dynamics of Background Adaptation in Xenopus laevis: Role of Catecholamines and Melanophore-Stimulating Hormone
}

\author{
I. D. van Zoest, P. S. Heljmen, P. M. J. M. Cruljsen, and B. G. Jenks \\ Department of Animal Physiology, Faculty of Science, University of Nijmegen, Toernooiveld, \\ 6525 ED Nijmegen, The Netherlands
}

Accepted June 5, 1989

\begin{abstract}
The pars intermedia of the pituitary gland in Xenopus laevis secretes $\alpha$-melanophore-stimulating hormone ( $\alpha$-MSH), which causes dispersion of pigment in dermal melanophores in animals on a black background. In the present study we have determined plasma levels of $\alpha$-MSH in animals undergoing adaptation to white and black backgrounds. Plasma values of black-adapted animals were high and decreased rapidly after transfer to a white background, as did the degree of pigment dispersion in dermal melanophores. Plasma MSH values of white-adapted animals were below the detection limit of our radioimmunoassay. Transfer of white animals to a black background resulted in complete dispersion of melanophore pigment within a few hours, but plasma MSH levels remained low for at least $24 \mathrm{hr}$. This discrepancy between plasma MSH and degree of pigment dispersion suggested the involvement of an additional factor for stimulating dispersion. Results of in vitro and in vivo experiments with receptor agonists and antagonists indicated that a $\beta$-adrenergic mechanism, functioning at the level of the melanophore, is involved in the stimulation of pigment dispersion during the early stages of background adaptation. () 1989 Academic Press, Inc.
\end{abstract}

The pars intermedia of the amphibian pituitary gland produces melanophorestimulating hormone (MSH), a peptide that causes dispersion of pigment in dermal melanophores. This hormone is the endocrine link in a neuroendocrine reflex regulating skin color; in animals on a black background the hormone is released and consequently their skin is dark (Bagnara and Hadley, 1973). Previous in vitro studies have shown that the amphibian Xenopus laevis has the potential to produce and secrete two forms of MSH, the highly melanotropic N-terminally acetylated form, $\alpha-\mathrm{MSH}$, and the less melanotropic, nonacetylated form, desacetyl- $\alpha$-MSH (Martens et al., 1981; Verburg-van Kemenade $e t$ al., 1987b). In an attempt to characterize the circulating forms of MSH during background adaptations, we experienced difficulty in demonstrating the presence of MSH in blood plasma of animals trans- ferred from a white to a black background, although a rapid pigment dispersion was observed in dermal melanophores. In the more extensive study of plasma MSH levels reported in this paper, we indeed found that plasma MSH levels increase only very slowly during the process of black background adaptation. This observation suggested to us that a factor besides MSH must be involved in the stimulation of pigment dispersion.

There have been reports that catecholamines induce pigment dispersion in $X$. laevis (Burgers et al., 1953; Brouwer and van de Veerdonk, 1972; Graham, 1961; van de Veerdonk and Konijn, 1970). The presence of endogenous catecholamines in the skin (Brouwer and van de Veerdonk, 1969) suggests a possible involvement in the regulation of pigment dispersion. Therefore, in the present studies we have also investigated the possible role of catecholamines, 
functioning at the level of the melanophore, in the regulation of dermal melanophores during background adaptations.

\section{METHODS}

\section{Animals}

Two strains of $X$. laevis were used: Strain I was obtained from the Hubrecht laboratory, The Netherlands Institute for Developmental Biology, Utrecht. Strain II was from the Faculty of Science, University of Nijmegen. The former strain has been a laboratory stock for many generations; the latter was obtained by crossing the $F_{1}$ generation of animals obtained from Africa. The animals were bred and raised on a gray background at a temperature of $22^{\circ}$. Three weeks prior to the experiments, four or five young adults (1 year) of both sexes were placed in a white or a black bucket, under constant illumination, to adapt to white or black background. In all experiments the melanophore index (MI) was scored following the criteria of Hogben and Slome (1931). MI = 5 represents full dispersion, and MI = 1 complete aggregation, of melanin.

\section{Radioimmunoassay}

Antiserum was raised against synthetic $\alpha$-MSH (Sigma M4135) coupled with carbodiimide to thyroglubulin (Sigma type I) according to the method of Hong et al. (1983). Blood was collected from an ear vein of the rabbits (New Zealand white) and serum prepared. In the radioimmunoassay (RIA) of this study serum of the ninth bleeding (L9) was used. One volume of serum was mixed with one volume of glycerol and stored at $-20^{\circ}$.

In the RIA the final dilution of antiserum was $1: 30,000$. The total incubation volume was $500 \mu \mathrm{l}$. After $48 \mathrm{hr}$ incubation at $4^{\circ}$, in the presence of trasylol (trypsin inhibitor, $45 \mathrm{KIU} /$ tube, Serva), bound and unbound $\alpha$-MSH were separated either by polyethyleneglycol/ovalbumin (15\%/2.4\%) precipitation or by the use of a second antibody coupled to cellulose beads (Sac-Cel, Wellcome, donkey anti-rabbit). Crossreactivity with des- $\alpha$-MSH was essentially $100 \%$ but the antiserum showed almost no cross-reactivity with $\mathrm{ACTH}_{1-24}$ or $\mathrm{ACTH}_{1-39}(<0.5 \%)$. The detection limit was $10 \mathrm{pg} /$ tube (40 $\mathrm{pg} \mathrm{MSH} / \mathrm{ml}$ plasma) with the PEG/ albumin method and $2.5 \mathrm{pg} /$ tube (10 pg $\mathrm{MSH} / \mathrm{ml}$ plasma) with the Sac-Cel method. The interassay variation was $13 \%$ and the intraassay variation, $6 \%$.

\section{Plasma Preparation for Radioimmunoassay}

Xenopus were adapted to a black or white background according to different protocols (see Results). At different times after transfer the animals were sac- rificed by decapitation; trunk blood was collected in an ice-cold saline solution containing $\mathrm{Na}_{2}$ EDTA ( $2 \mathrm{mM}$ ) and trypsin inhibitor $(40,000 \mathrm{KIU} /$ tube, Serva). After centrifugation each plasma sample was loaded on a Baker octadecyl-C18 column, the column was washed three times with 4\% 1-propanol in buffer B $\mathbf{0 . 1 4} M$ pyridine/0.5 $M$ formic acid, $\mathrm{pH} 3.0$ ), and the MSH was then eluted with $40 \%$ 1-propanol in buffer B. After addition of $50 \mu \mathrm{g}$ bovine serum albumin (BSA; Sigma, fraction $V$ ) the eluate was evaporated to dryness (Speed-vac concentrator, Savant), and stored at $4^{\circ}$ until assay. Before assay the samples were redissolved in RIA buffer $\left(0.02 M\right.$ sodium barbital, 0.2 g/iter $\mathrm{NaN}_{3}$, 3 gliter BSA, pH 8.6).

\section{Pigment Dispersion in Isolated Webs}

Web tissue was obtained from white-adapted animals. Small pieces $\left( \pm 25 \mathrm{~mm}^{2}\right)$ were placed in wells containing amphibian Ringer's solution [112 $\mathrm{mM}$ $\mathrm{NaCl}, 2 \mathrm{~m} M \mathrm{KCl}, 2 \mathrm{mM} \mathrm{CaCl}, 15 \mathrm{~m} M$ Hepes (Calbiochem, Ultrol grade), $0.3 \mathrm{mg} / \mathrm{ml}$ BSA (Sigma, fraction $\mathrm{V}), 2 \mathrm{mg} / \mathrm{ml}$ glucose, $1 \mu \mathrm{g} / \mathrm{ml}$ ascorbic acid, $\mathrm{pH}$ 7.4]. Solutions of the neurotransmitters or drugs to be tested were prepared in amphibian Ringer's solution and added to the wells. After various time periods, the melanophore index was recorded.

The following substances were tested: adrenaline, noradrenaline, propranolol, isoproterenol, phenylephrine, all from Sigma. Phentolamine (Regitine) was from Ciba-Geigy. Concentrations used are given in the legends to the figures.

\section{Treatment with Receptor Agonists and Antagonists in Vivo}

Black or white animals were intraperitoneally injected with the $\beta$-adrenergic receptor antagonist propranolol in saline in a volume of $0.1 \mathrm{ml}$. Saline-injected animals served as controls. The MI was recorded during background adaptation. In some experiments the specific $\mathrm{GABA}_{b}$ receptor agonist baclofen (CibaGeigy) was injected. Concentrations used are given in the legends to the figures.

\section{Calculations and Statistics}

Results are shown as means \pm SEM. Student's $t$ test (two-tailed) was used to determine differences between means. A $P$ value less than 0.05 was considered to indicate significance.

\section{RESULTS}

\section{Plasma MSH and Pigment Dispersion}

During black-to-white background adap- 
tation, plasma MSH levels of strain I animals dropped rapidly, from about $130 \mathrm{pg} / \mathrm{ml}$ to a nondetectable level within $30 \mathrm{~min}$. The MI dropped significantly within $30 \mathrm{~min}$ and decreased gradually thereafter (Fig. 1a). In plasma of strain II animals, the changes were comparable but the response was somewhat slower: plasma MSH dropped
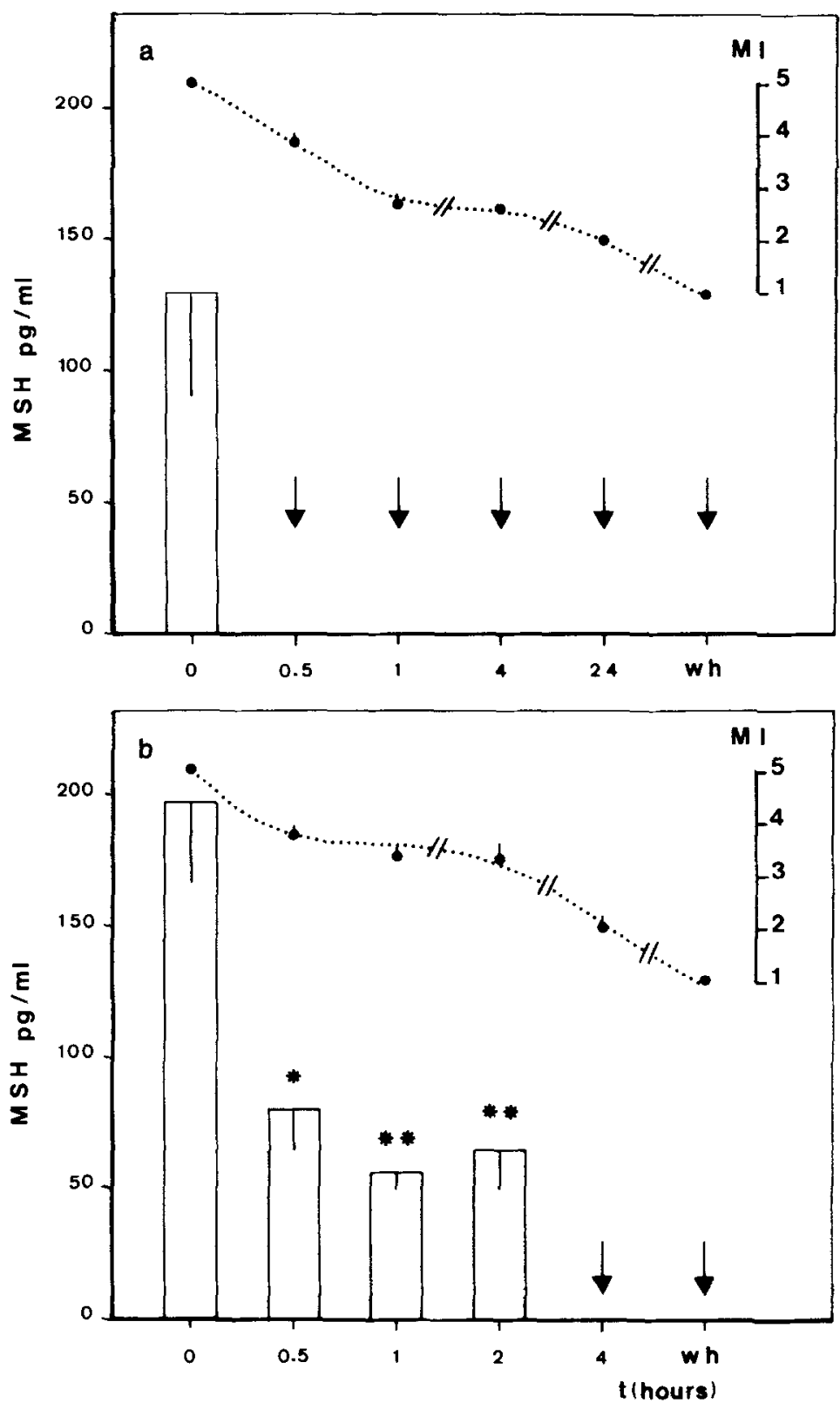

FIG, 1. Plasma MSH values (mean - SEM, $n=4$ ) and melanophore index (MI; mean + SEM) of black-adapted animals after transfer to a white background for (a) strain I animals and (b) for strain II animals. wh are the 3-week white-adapted animals. Arrows indicate that the plasma MSH level was below the detection limit of the RIA. Significance: ${ }^{*} P<0.05,{ }^{* *} P<0.01$, compared with $t=0$. MI: all mean values were significantly different from that of $t=0(P<0.001)$. 
from 200 to $80 \mathrm{pg} / \mathrm{ml}$ within $30 \mathrm{~min}$ and was not detectable after $4 \mathrm{hr}$; the $\mathrm{MI}$ dropped significantly to 3.8 within $30 \mathrm{~min}$ and decreased further thereafter (Fig. 1b).

In white-adapted animals transferred to a black background the MI of strain I animals increased rapidly, reaching 4.5 within $1 \mathrm{hr}$ of transfer, whereas the plasma MSH level remained below detection for at least $24 \mathrm{hr}$. The mean plasma MSH level in long-term black-adapted animals was $385 \mathrm{pg} / \mathrm{ml}$ (Fig. 2a). The melanophores of strain II animals responded more slowly: the MI increased to 4.5 after $4 \mathrm{hr}$ on a black background. Plasma MSH became detectable within $4 \mathrm{hr}$ but remained at relatively low levels for several days. In long-term black-adapted animals the mean plasma MSH level was $215 \mathrm{pg} / \mathrm{ml}$ (Fig. 2b).

\section{Effect of Baclofen on Pigment Dispersion in Vivo}

Treatment of white-adapted animals with baclofen prior to transfer to a black background delayed pigment dispersion in dermal melanophores (Fig. 3a). Results shown are for strain I animals. In animals adapted for $60 \mathrm{~min}$ to a black background (i.e., a period sufficient to reach MI greater than 4), baclofen treatment had no significant effect on pigment dispersion, whereas the same treatment of long-term black-adapted animals resulted in a decrease in the $\mathrm{MI}$ from 5 to 2.3 after $180 \mathrm{~min}$ (Fig. 3b). Results shown are for strain I animals; results for strain II animals are similar.

\section{Pigment Dispersion in Isolated Webs}

Adrenaline and noradrenaline caused pigment dispersion in Xenopus isolated web, reaching $M I=4-5$ within $1 \mathrm{hr}$ (Fig. 4). These effects were dose dependent (data not shown). The effect of adrenaline was blocked by the $\beta$-adrenergic receptor antagonist propranolol, but not by the $\alpha$-blocker phentolamine (data not shown). Isoproterenol, a $\beta$-receptor agonist, caused a disper- sion similar to that caused by (nor)adrenaline, which was blocked by propranolol; phenylephrine, an $\alpha$-receptor agonist, had no effect on dispersion (Fig. 5). All results shown are for strain I animals.

\section{Effect of Propranolol on Pigment Dispersion in Vivo}

In white-adapted animals propranolol delayed the dispersion after transfer to a black background, compared with saline-injected controls (Fig. 6). Results shown are for strain I animals; similar but less pronounced results were obtained for strain II animals. For both strains, the injection of a cocktail of propranolol and baclofen completely prevented pigment dispersion in white-adapted animals transferred to a black background (Fig. 7). Results shown are for strain II animals.

\section{DISCUSSION}

The observation that long-term blackbackground-adapted animals had high circulating levels of $\mathrm{MSH}$ and long-term white-background-adapted animals had low levels is consistent with the classical view of the neuroendocrine regulation of dermal melanophores. There is an earlier report of MSH plasma levels in Xenopus laevis, namely that of Wilson and Morgan (1979). They measured plasma MSH levels in $\mathrm{Xe}$ nopus adapted for 4 to 7 days to either a white, gray, or black background and showed that there is a positive correlation between melanophore index and circulating levels of MSH. They concluded that in long-term adapted animals, the circulating level of MSH is the crucial factor in determining the degree of pigment dispersion in dermal melanophores. Our results concerning plasma MSH values of long-term whiteand black-adapted animals support their conclusion.

To our knowledge, the present study is the first in which plasma MSH values have been examined in animals during the adap- 

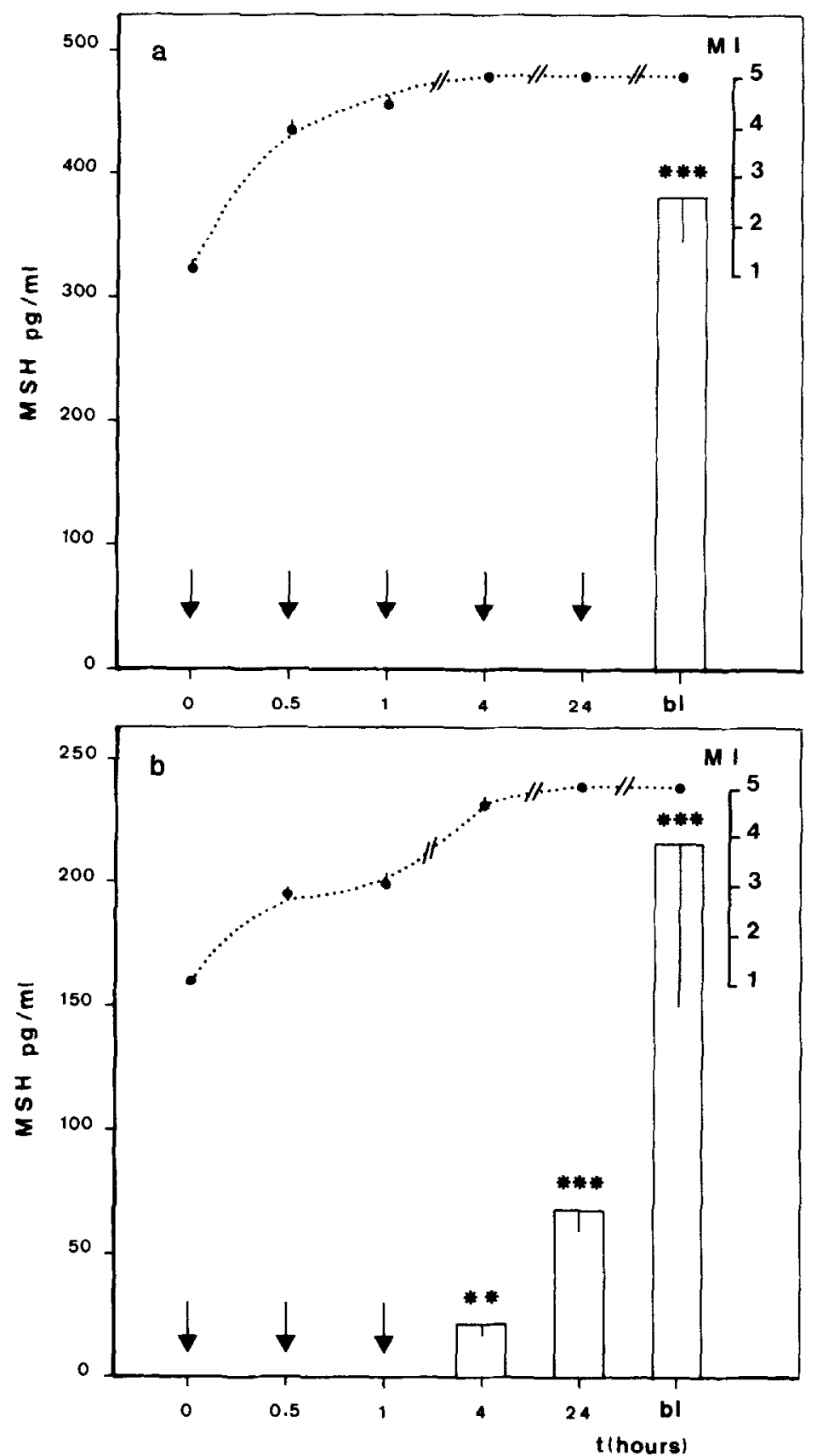

FIG. 2. Plasma MSH values (mean - SEM, $n=4$ ) and melanophore index (MI; mean + SEM) of white-adapted animals after transfer to a black background for (a) strain I animals and (b) for strain II animals. bl are the 3-week black-adapted animals. Arrows indicate that the plasma MSH level was below the detection limit of the RIA. Significance: ${ }^{* *} P<0.01,{ }^{* * *} P<0.001$, compared with $t=0$. MI: all mean values were significantly different from that of $t=0(P<0.001)$. 

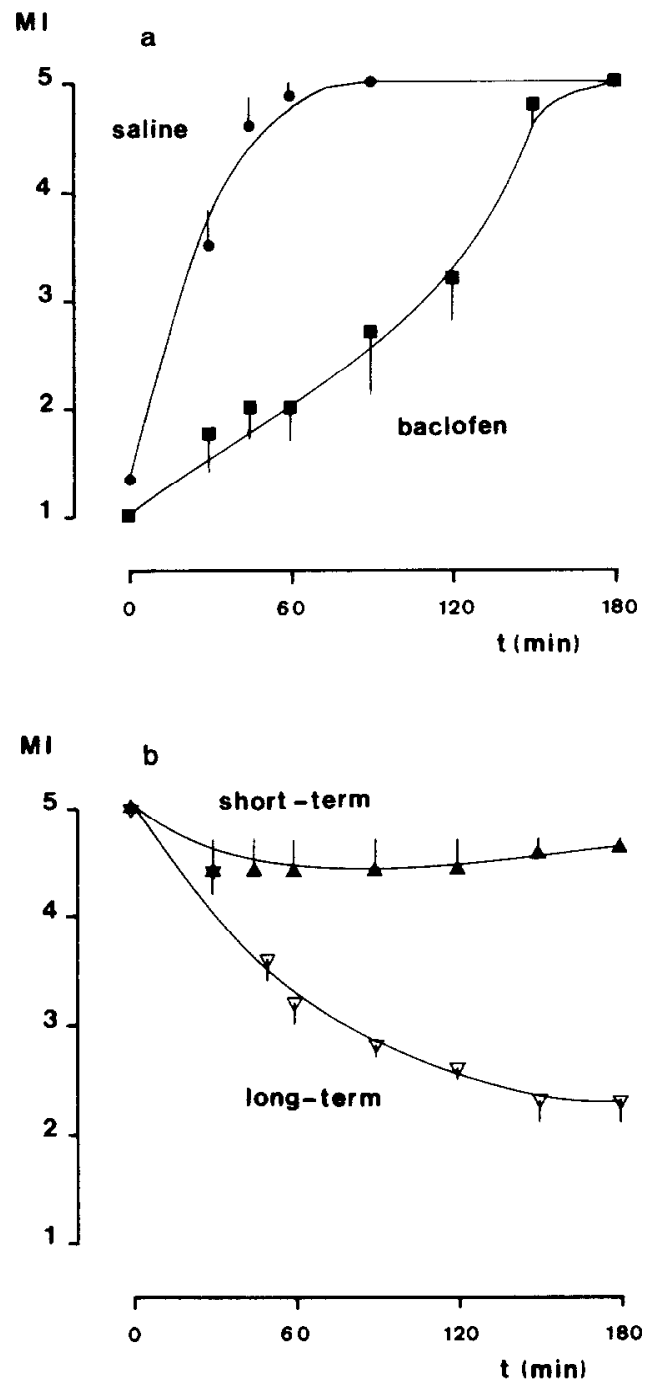

FIG. 3. (a) Melanophore index (MI) of whiteadapted animals after ip injection at $t=0$ with saline (controls) or baclofen $\left(3.3 \times 10^{-8} \mathrm{~mol} / \mathrm{g}\right.$ body wt). Animals were placed on a black background after injection. Results are expressed as means + SEM (saline, $n=3-5$ ) and means - SEM (baclofen, $n=4$ ). Differences between groups were significant at $t=30$ $\min (P<0.05) ; t=45 \min (P<0.01) ; t=60 \mathrm{~min}(P$ $<0.001)$; and $t=90 \mathrm{~min}(P<0.01)$. (b) MI of longterm ( 3 weeks) black-adapted animals after ip injection at $t=0$ with baclofen $\left(3.3 \times 10^{-8} \mathrm{~mol} / \mathrm{g}\right.$ body wt) and of short-term ( $1 \mathrm{hr}$ ) black-adapted animals injected with the same dose of baclofen. Animals were returned to a black background after injection. Results are expressed as means + SEM (short-term, $n=4$ ) and means - SEM (long-term, $n=4$ ). Differences between groups were significant at $t=60 \mathrm{~min}(P<$ $0.05) ; t=90 \mathrm{~min}, t=120 \mathrm{~min}(P<0.01) ;$ and $t=150$ $\min , t=180 \min (P<0.001)$.

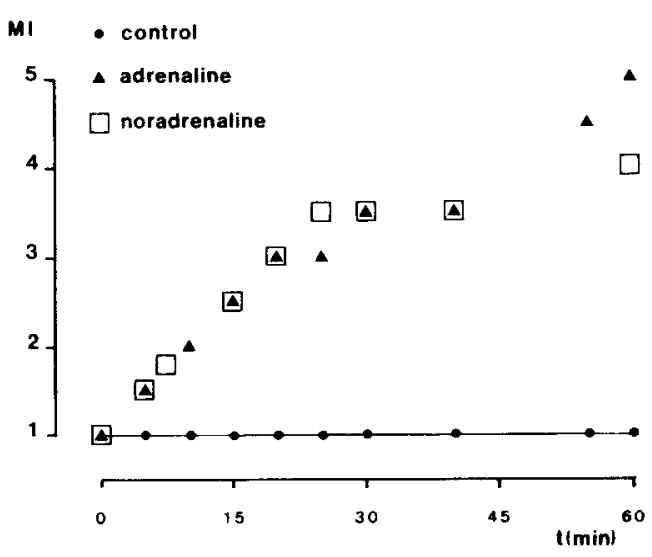

FIG. 4. MI of isolated webs from white-adapted animals submersed in amphibian Ringer's supplemented with adrenaline $\left(10^{-6} M\right)$ or noradrenaline $\left(10^{-6} M\right)$. The averages of three web pieces per well are shown.

tive process, as opposed to the long-term adaptations mentioned earlier. The rapid drop in plasma MSH in black animals placed on a white background and the concomitant decrease in melanophore index are consistent with the view that adaptation to a white background results from inhibition of MSH secretion.

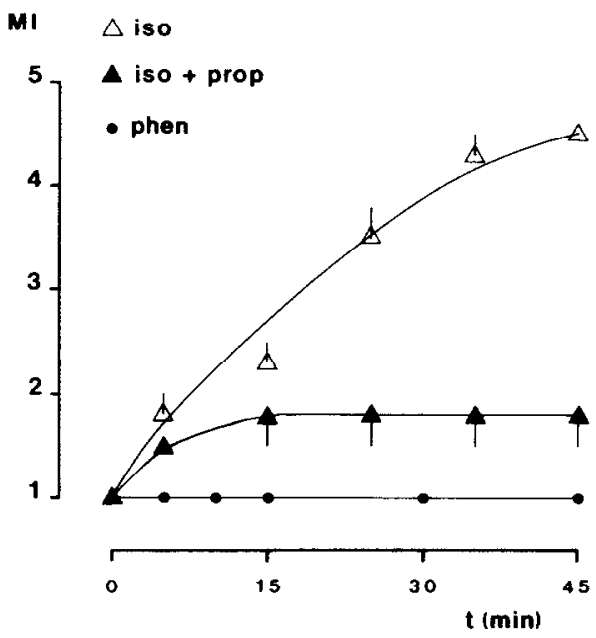

FIG. 5. MI of isolated webs from white-adapted animals submersed in amphibian Ringer's supplemented with isoproterenol (iso; $10^{-6} M$ ) \pm propranolol (prop; $10^{-4} M$ ) or phenylephrine (phen; $10^{-6} M$ ). Results are means \pm SEM of three wells. Iso and iso + prop were significantly different at $t=25 \mathrm{~min}(P<0.05)$; and $t=$ $35 \mathrm{~min}, t=45 \mathrm{~min}(P<0.01)$. 


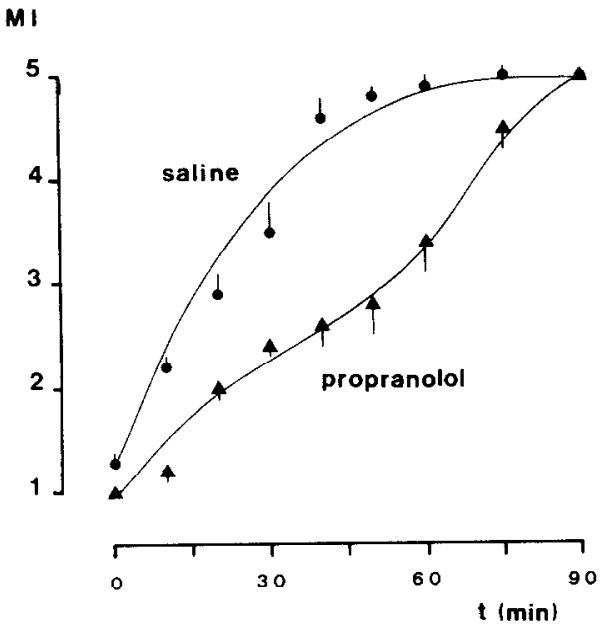

FIG. 6. MI of white-adapted animals after ip injection at $t=0$ of $0.1 \mathrm{ml}$ saline (controls) or propranolol $\left(5 \times 10^{-9} \mathrm{~mol} / \mathrm{g}\right.$ body wt). Animals were placed on a black background after injections. Results are expressed as means + SEM (saline, $n=3-5$ ) and means - SEM (propranolol, $n=5$ ). Differences between groups were significant at $t=10 \mathrm{~min}(P<0.001) ; t=$ $20 \mathrm{~min}(P<0.01) ; t=30 \mathrm{~min}(P<0.01) ; t=40 \mathrm{~min}$ $(P<0.001) ; t=50 \mathrm{~min}(P<0.001) ; t=60 \mathrm{~min}(P<$ $0.01)$; and $t=75 \mathrm{~min}(P<0.05)$.

We observed a clear discrepancy between pigment dispersion and plasma MSH levels initially after transfer of animals from a white to a black background. Pigment was fully dispersed within hours of transfer, whereas it took a number of days for plasma MSH values to approach those of long-term black-adapted animals. Previous studies show that following transfer from a white to a black background, the capacity of the pars intermedia to synthesize (Jenks et al., 1977; Loh and Gainer, 1977) and acetylate (Verburg-van Kemenade et al., $1987 \mathrm{~b}) \mathrm{MSH}$ is only very slowly developed, taking a number of days to achieve the full capacity of long-term black-adapted animals. It had always been assumed that animals depend on release of stored MSH to maintain pigment dispersion during the period the pars intermedia is acquiring its full biosynthetic capacity. Our results clearly question the validity of this assumption.

Earlier studies show that treatment of

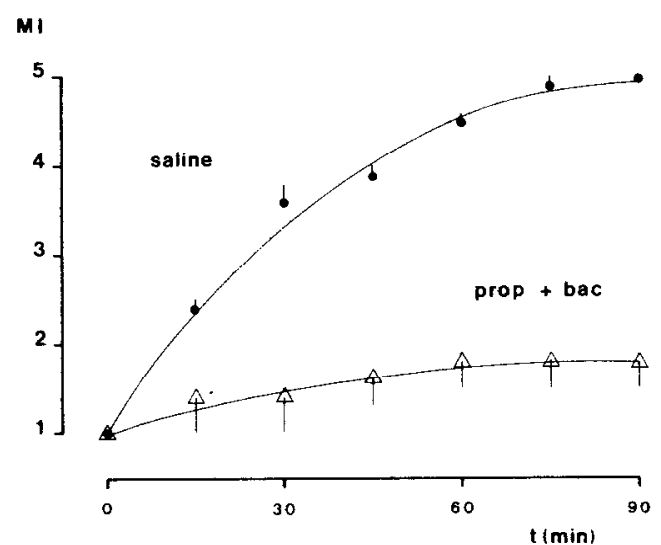

FIG. 7. MI of white-adapted animals after ip injection at $t=0$ with saline (controls) or a cocktail of baclofen (bac; $3.3 \times 10^{-8} \mathrm{~mol} / \mathrm{g}$ body wt) and propranolol (prop; $5 \times 10^{-8} \mathrm{~mol} / \mathrm{g}$ body wt). Animals were placed on a black background after injections. Results are expressed as means + SEM (saline, $n=8$ ) and means - SEM (bac + prop, $n=4)$. Differences between groups were significant at $t=15 \mathrm{~min}(P<$ $0.01)$ and $t=30,45,60,75$, and $90 \mathrm{~min}(P<0.001)$.

black-adapted Xenopus with baclofen, a MSH release-inhibiting factor, which acts at the level of the MSH cell (Verburg-van Kemenade et al., 1986a), leads to rapid blanching of the animals (Verburg-van Kemenade et al., 1987a), most likely a result of its inhibition of MSH secretion. In the present in vivo experiments we gave the same treatment to white-adapted animals, which were subsequently transferred to a black background. The results show that while there was a slower rate of pigment dispersion, indicating at least a partial role for the pars intermedia in stimulating dispersion, these animals nonetheless showed an increase in melanophore index. Remarkably, administration of baclofen to animals that had been placed on a black background only $60 \mathrm{~min}$ earlier ( $\mathrm{MI}=5$ ) had no effect on pigment dispersion. As expected, the same treatment in long-term black-adapted animals caused rapid aggregation of pigment, suggesting inhibition of MSH release. Altogether the present results with baclofen are consistent with the concept that long-term adaptation to a black back- 
ground relies primarily on MSH for maintenance of pigment dispersion, while, during the adaptive process itself, a factor other than MSH must also be involved in achieving full melanin dispersion.

In considering the possible identity of the factor responsible for pigment dispersion in animals undergoing adaptation to a black background, our attention was drawn to earlier studies showing that adrenaline causes pigment dispersion in Xenopus melanophores (Burgers et al., 1953; Burgers, 1956), functioning through a $\beta$-adrenergic receptor (Graham, 1961; van de Veerdonk and Konijn, 1970). Our experiments with isolated Xenopus webs confirm that the melanophores are sensitive to adrenaline and noradrenaline. Using isoproterenol and propranolol, we also confirm that this stimulatory action is through a $\beta$-adrenergic receptor.

To establish whether a $\beta$-adrenergic receptor mechanism could be involved in inducing pigment dispersion during the adaptation of Xenopus to a black background, we performed in vivo experiments. Treatment of white animals with the $\beta$-blocker propranolol slowed the rate of pigment dispersion when these animals were subsequently placed on a black background. It is important to note that the pars intermedia of Xenopus, unlike that of some other amphibian species (Bower et al., 1974; Tonon et al., 1983), is devoid of $\beta$-adrenergic receptors for the regulation of MSH secretion (Verburg-van Kemenade et al., 1986b). Therefore, we believe that the present results indicate the functioning of a $\beta$-adrenergic mechanism at the level of the melanophore during the process of black background adaptation. The observation that propranolol had no effect on pigment dispersion in long-term black-adapted $\mathrm{Xe}$ nopus (data not shown) corroborates the view that maintenance of dispersion in those animals is achicved primarily through the action of MSH.

There was a clear strain difference in both the speed of the melanophore response to changes in background and the magnitude of the response to propranolol treatment. The melanophores of strain I responded more rapidly to background transfer, and also gave a more pronounced response to the $\beta$-adrenergic receptor blocker, than those of strain II. These obscrvations could reflect strain differences in the relative contribution of the $\beta$-adrenergic mechanism versus $\mathrm{MSH}$ in the early stages of black background adaptation, with strain I relying more heavily on the $\beta$-adrenergic mechanism. Treatment of animals with the $\beta$-adrenergic receptor antagonist in combination with the MSH release-inhibiting factor baclofen completely eliminated the ability of the animals to adapt to a black background. Treatment with either drug alone was only partially effective. Thus, our data provide evidence that pigment dispersion during the early stages of black background adaptation involves both $\beta$-adrenergic and MSH stimulatory mechanisms. Although our results indicate that quantitative differences in the adaptive response of strain I and II animals were present, qualitatively their responses were comparable.

There are several potential sources of catecholamines for physiological regulation of melanophores. Involvement of circulating catecholamines from the adrenal gland seems unlikely as only a very slight transient pigment expansion (maximum $\mathrm{MI}=$ 2.5 ) in dermal melanophores occurs during acute stress (Burgers et al., 1953; Burgers, 1956), when circulating catecholamines are cxpected to be elevated. Although there is no evidence for direct autonomic innervation of melanophores in Xenopus, the skin is reported to be rich in catecholamines (Brouwer and van de Veerdonk, 1969), probably located in skin glands whose secretion is under autonomic control. It is conceivable that catecholamines in such secretions or from nerve terminals in the vicinity of the melanophores could generate a local catecholamine concentra- 
tion of sufficient magnitude to have a physiological function during background adaptation. In preliminary in vivo experiments to investigate this, we have excised web pieces (thus severing any autonomic nerve fibers) and transplanted the web tissue to the back of the animal (van Zoest and Jenks, unpublished). Vascularization of the autotransplant was reestablished within a few days, as demonstrated by the full response of the melanophores of the transplant to injections of $\alpha-\mathrm{MSH}$. In contrast, these melanophores showed retarded pigment dispersion when the animal was placed on a black background, an observation that supports the view that the action of nerve fibers could be an important element in inducing pigment dispersion during physiological adaptations.

In conclusion, we have presented data that demonstrate that in Xenopus, MSH is not the only factor involved in stimulating dermal melanophores during the process of adaptation to a black background. The results indicate the involvement of a $\beta$-adrenergic mechanism, and, therefore, we attach physiological significance to the presence of this receptor type on the melanophore. We conclude that the $\beta$-adrenergic mechanism plays an important role in stimulating the melanophores during the period in which the pars intermedia is acquiring its full biosynthetic and acetylation capacity.

\section{ACKNOWLEDGMENT}

The investigation was supported by the Foundation for Biological Research (BION, Project 426.263), which is subsidized by The Netherlands Organization for Scientific Research (NWO).

\section{REFERENCES}

Bagnara, J. T., and Hadley, M. E. (1973). "Chromatophores and Color Change: The Comparative Physiology of Animal Pigmentation." PrenticeHall, Englewood Cliff, NJ.
Bower, A., Hadley, M. E., and Hruby, V. J. (1974). Biogenic amines and control of melanophore stimulating hormone release. Science 184, 70-72.

Brouwer, E., and van de Veerdonk, F. C. G. (1969). Identification of a catecholamine in the skin of the toad, Xenopus laevis, and the relation to the physiological melanophore reaction. Experientia 25, 391-392.

Brouwer, E., and van de Veerdonk, F. C. G. (1972). Possible involvement of $\alpha$ - and $\beta$-receptors in the natural colour change and the MSH-induced dispersion in Xenopus laevis in vivo. Eur. J. Pharmacol. 17, 234-239.

Burgers, A. C. J. (1956). "Investigations into the Action of Certain Hormones and Other Substances on the Melanophores of the South African Clawed Toad, Xenopus laevis." Thesis State University, Utrecht

Burgers, A. C. J., Boschman, Th. A. C., and van de Kamer, J. C. (1953). Excitement darkening and the effect of adrenaline on the melanophores of Xenopus laevis. Acta Endocrinol. 14, 72-82.

Graham, J. D. P. (1961). The response to catecholamines of the melanophores of Xenopus laevis. $J$. Physiol. (London) 158, 5P-6P.

Hogben, L. T., and Slome, D. (1931). The pigmentary effector system. VI. The dual character of endocrine coordination in amphibian color change. Proc. R. Soc. London Ser. B 108, 10-53.

Hong, J-S., Yoshikawa K., and Hendren, R. W. (1983). Measurement of $\beta$-endorphin and enkephalins in biological tissues and fluids. In "Methods in Enzymology" (P. M. Conn, Ed.), Vol. 103, pp. 547-564. Academic Press, Orlando, FL.

Jenks, B. G., van Overbeeke, A. P., and McStay, B. F. (1977). Synthesis, storage and release of MSH in the pars intermedia of the pituitary gland of Xenopus laevis. Canad. J. Zool. 55, 922-927.

Loh, Y. P., and Gainer, H. (1977). Biosynthesis, processing, and control of release of melanotropic peptides in the neurointermediate lobe of Xenopus laevis. J. Gen. Physiol. 70, 37-58.

Martens, G. J. M., Jenks, B. G., and van Overbeeke, A. P. (1981). $N^{\alpha}$-acetylation is linked to $\alpha$-MSH release from pars intermedia of the amphibian pituitary gland. Nature (London) 294, 558-560.

Tonon, M. C., Leroux, P., Stoeckel, M. E., Jegou, S., Pelletier, G., and Vaudry, H. (1983). Catecholaminergic control of $\alpha$-melanocyte-stimulating hormone ( $\alpha \mathrm{MSH})$ release by frog neurointermediate lobes in vitro. Endocrinology 112, 133-141.

Van de Veerdonk, F. C. G., and Konijn, Th. M. (1970). The role of adenosine $3^{\prime}, 5^{\prime}$-cyclic monophosphate and catecholamines in the pigment migration process in Xenopus laevis. Acta Endocrinol. 64, 364-376. 
Verburg-van Kemenade, B. M. L., Jenks, B. G., and Driessen, A. G. J. (1986a). GABA and dopamine act directly on melanotropes of Xenopus to inhibit MSH secretion. Brain Res. Bull. 17, 697-704.

Verburg-van Kemenade, B. M. L., Jenks, B. G., and van Overbeeke, A. P. (1986b). Regulation of melanotropin release from the pars intermedia of the amphibian Xenopus laevis: Evaluation of the involvement of serotonergic, cholinergic, or adrenergic receptor mechanisms. Gen. Comp. Endocrinol. 63, 471-481.

Verburg-van Kemenade, B. M. L., Jenks, B. G., Lenssen, F. J. A., and Vaudry, H. (1987a). Char- acterization of GABA receptors in the neurointermediate lobe of the amphibian Xenopus laevis. Endocrinology 120, 622-628.

Verburg-van Kemenade, B. M. L., Jenks, B. G., and Smits, R. J. M. (1987b). $N$-terminal acetylation of MSH in the pars intermedia of Xenopus laevis is a physiologically regulated process. Neuroendocrinology 46, 289-296.

Wilson, J. F., and Morgan, M. A. (1979). $\alpha$-Melanotropin-like substances in the pituitary and plasma of Xenopus laevis in relation to colour change responses. Gen. Comp. Endocrinol. 38, 172-182. 